\title{
Determination of stresses in salt rocks by hydraulic fracturing: Case-study
}

\author{
Arkady Leontiev, Ekaterina Rubtsova ${ }^{*}$ and Alexander Skulkin
}

Institute of Mining, Siberian Branch, Russian Academy of Sciences. 630091 Novosibirsk, Russia

\begin{abstract}
The paper presents the experimental results of stress assessment in salt rock mass around underground excavations in Solikamsk Mines 1, 2 and 3, Uralkali, at the Upper Kama potash deposit. The experiments were a part of the geomechanical research aimed at justification of project designs and engineering solutions made in selection of safe and efficient mining methods, including safety of watertight strata. The experimental works were accomplished using the measurement and computation system Gidrorazryv designed at the Institute of Mining, SB RAS. In the salt rock testing, the system was equipped with new-design downhole survey tool and wireless communication between pressure sensors and portable computer. The sites for measurement stations were selected with regard to current mining situation, distance between the sites and stoping front, absence of undermining or overmining and installability of drilling equipment. A particular attention was paid to a drilling tool capable of geometrically accurate drilling in salt rock mass, in compliance with standards of the hydraulic fracturing stress measurement technique. In the tests, the method of directional hydrofracturing with softening of measurement hole boundary by cutting initiation slots was implemented. All in all, 75 hydraulic fracturing tests were carried in adjacent rock mass in the mines. It is found that stress state in roof rocks of underground excavations is nonuniform: the vertical stress is similar to the calculated value due to weight of overlying rocks while the horizontal stresses exceed the gravitational stress by $2-3$ times.
\end{abstract}

Instrumental stress state monitoring in rock mass is essential at any stage of mineral mining. The knowledge on the parameters of effective stress fields is necessary for selecting appropriate project designs, as well as for operational planning and control. Among the methods of stress assessment in rocks in recent years, the top position belongs to hydraulic fracturing [1-5]. The mathematical apparatus of this technique needs no information on physical and mechanical properties of rocks when processing experimental data. This method is one of the few techniques applicable in deep downhole stress state control.

The experience of experimental stress assessment in salt rock mass is limited both in Russia and in the world [6-10]. The most efficient approach to stress control was found

* Corresponding author: rubth@misd.ru 
from among the methods of laboratory testing of rock samples using stress memory effect, as well as full-scale instrumental monitoring with such methods as borehole slotter, parallel drilling, compensation and long-gauge measurements. It is worthy of mentioning that the majority of these methods are difficult to use due to specific structure of salt rocks and owing to nonlinearity of salt rock deformation under loading. Furthermore, extra complexities arise in checkout operations implemented at a distance more than 3-6 $\mathrm{m}$ from the boundary of underground excavations.

Russian geomechanics applied hydraulic fracturing stress measurement technique in salt rock mass for the first time in the 1990s. The experiments were carried out in underground mines at the Upper Kama deposit in the Perm Krai [11]. The conclusion on the hydrostatic state of enclosing rock mass was drawn from the cumulative experimental results.

This paper describes the case-study of hydraulic fracturing application for stress measurement at the Upper Kama deposit in 2015-2016. The stress state tests were implemented in rocks around underground excavations of Solikamsk Mines 1, 2 and 3, Uralkali, in Solikamsk (Figure 1). The tests were the part of the geomechanical research undertaken by VNIIGalurgia, Saint-Petersburg, with a an intent to substantiate project designs and engineering solutions made when selecting safe and efficient mining methods for this deposit, including safety of watertight strata.

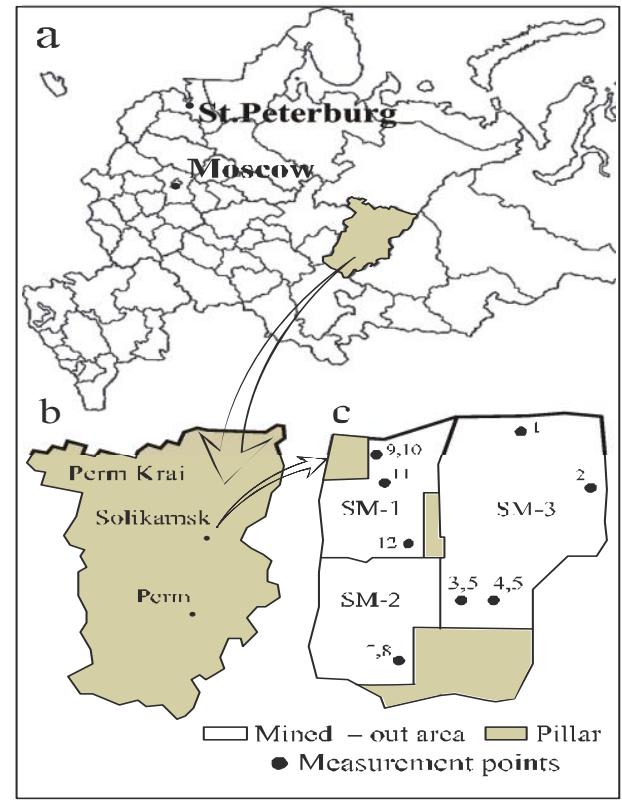

Fig. 1. Layout of measurement stations: a-Perm Krai in the map of Russia; b-Solikamsk in the territory of the Perm Krai; c-numbers are the measurement stations within the mining leases of Solikamsk Mines 1, 2 and 3.

The sites for the measurement stations were selected with regard to the current condition of mining. The decision-making on the measurement sites took into account the distances between the experimentation zones and stoping front, the absence of undermining or overmining of the test rock mass area and the accommodation possibility for drilling equipment. The geography of the selected sites is characterized below:

-Solikamsk Mine-3: measurement station No. 1 (main eastern ventilation drift, south), measurement station No. 2 (block 7, extraction panel 11, north), measurement stations Nos. 
3 and 5 (block 15, extraction panel 15, south), measurement stations Nos. 4 and 6 (block 15, extraction panel 17, south);

-Solikamsk Mine-2: measurement stations No. 7 and 8 (main southeastern haulage drift 2, between two declines);

-Solikamsk Mine-1: measurement stations Nos. 9 and 10 (northeastern undermining 1, block 1, drainage declines, 50 and $70 \mathrm{~m}$ away from the junction), measurement station No. 11 (northwestern undermining area 1, eastern block 2, panel ventilation drift), measurement station No. 12 (northwestern undermining area 1, eastern block 2, exploration opening).

In the standard design of a measurement station, a drill rig was set along the central axis of an underground excavation. Orthogonally to the central axis, three holes with diameter of $76 \mathrm{~mm}$ and to $10 \mathrm{~m}$ long were drilled. The central hole was oriented strictly vertically; the other two holes were drilled at the angles of 30 and 60 degrees to horizon.

The first-stage tests revealed essential complexity in straight-line drilling of measurement holes with quality walls and preset geometry in salt rock mass without a special tool. The drilling services of the test mines drilled holes which appeared inapplicable for the measurement tests. The holes were curved, had stepped or spiral-type roughnesses on the walls and were poorly cleanable from drill cuttings.

Thus, it was necessary to design a special drilling tool for high-precision drilling in salt rocks in compliance with requirements of hydraulic fracturing stress measurement. Moreover, aimed to cut down drilling time, the drilling-out technique was implemented. First, a pilot hole with diameter of 90-110 m and $5 \mathrm{~m}$ long was made using a bore bit. Then, the hole was drilled to the maximum length using a special drilling assembly.

From the tests of a number of designs, the satisfactory results were obtained with a drilling assembly composed of a starting borer with three-point drill bit KDS 76/sp33 with diameter of $76 \mathrm{~mm}$ (Figure 2) and a screw rod with external diameter of $74 \mathrm{~mm}$. Using this drilling tool, 26 measurement holes with total length of $120 \mathrm{~m}$ were drilled.

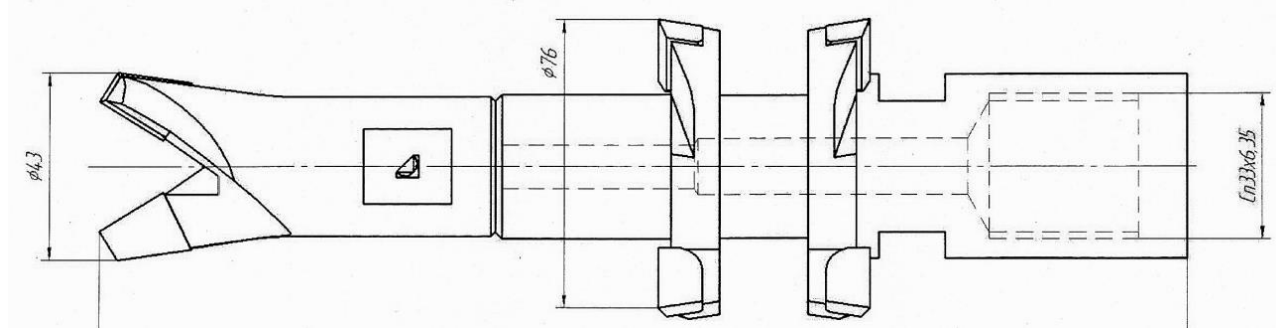

Fig. 2. Layout of starting borer with drill bit KDS 76/sp33.

In order that created fractures propagate orthogonally to the hole axis, a disk-like initiation slot was preliminary cut within the hydrofracturing interval. To this effect, slotters designed by Yuri Lekontsev at the Institute of Mining, SB RAS [12] were used. The design of the slotters takes into account physical and mechanical properties of salt rocks, as well as technical characteristics of the drilling equipment.

The tests of the hydraulic fracturing stress measurement technique also involved the measurement and computation system Gidrorazryv (the Russian word for hydraulic fracturing) created at the the Institute of Mining, SB RAS [13]. Figure 3 shows schematically a downhole survey tool included in the structure of the measurement and computation system. The tool has four packers and two cylinders to perform axial compression. The feature of this design is synchronous operation of the packers made operational by the same-type power devices (cylinders). Furthermore, this design prevents penetration of working fluid from the packer-to-packer interval (during hydraulic fracturing) to the contact zone of the packers and borehole walls, or beyond, i.e. the flow- 
past effect is eliminated. The downhole survey tool is designed so that it is possible to vary the length of the packer-to-packer interval by changing the central part of the bearing rod of the device. In the hydraulic fracturing tests, the packer-to-packer interval in the zones of slots-stress concentrators made 2-3 diameters of the hole. The downhole survey tool with packers reinforced by cylindrical springs was successfully trialed during the full-scale hydrofracturing tests. The laboratory pretesting of such packers proved firmer adherences of the envelope of such packers to borehole walls. Moreover, the spring-reinforced packers are less subjected to wear (abrasion of external surface when the survey tool is moved along the hole) owing to more reliable reset after compression relaxation.

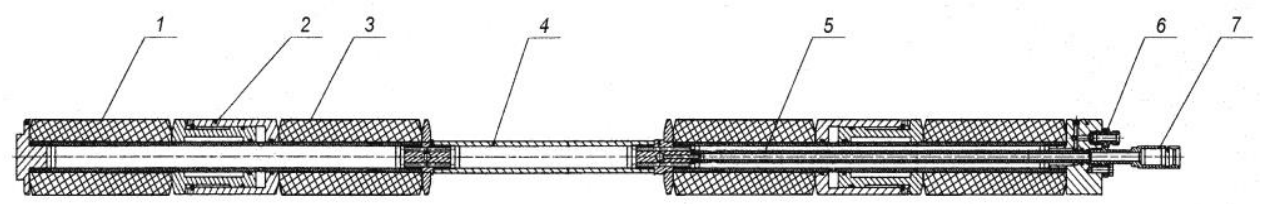

Fig. 3. Layout of downhole survey tool: 1, 3-packers; 2-hydraulic cylinder; 4-body of the tool; 5-feed channel of working fluid to packer-to-packer interval; 6, 7-inlets to be connected with pressure lines.

The system Gidrorazryv also had wireless communication with portable computer. During the tests, the analog signal from a sensor goes to a data conversion and transmission device (in a separate housing) to be converted to a series of bytes by RS232 protocol and to be sent to PC via Bluetooth-type channel. The wireless communication ensures mobility and comfort of mine experimentation.

The Gydrorazryv software provided visual display of pressure variation in the packerto-packer interval in the course of the tests, which allowed current evaluation of the test quality. The test data on hydraulic fracturing were stored on the hard disk of PC and were available for the subsequent interpretation and analysis.

The pressure-time diagrams (e.g., in Figure 4) were used to determined: $P_{c}$-fracture initiation pressure; $P_{r}$-re-opening pressure; $P_{s}$-shut-in pressure at the equilibrium of the open created fracture when the fluid pressure balances the rock mass stresses oriented normally to the fracture plane. The fracture pressure-to-stress transform was carried out using the relations below:

$$
P_{c}=3 \sigma_{\min }-\sigma_{\max }+T_{c} ; P_{r}=3 \sigma_{\min }-\sigma_{\max } ; P_{s}=\sigma_{\min } .
$$

Here, $\sigma_{\min }, \sigma_{\max }$ are the minimum and maximum horizontal stresses, respectively; $T_{c}$ is the shear strength of rocks. The shut-in pressure in the test data interpretation was determined by two methods: (1) $P$ relative to $\log \Delta t$, where $P$-pressure, $\Delta t$-time from the moment of dip of the curve; (2) $d P / d t$ relative to $P$ [14].

Solikamsk Mine-3. The experimental hydraulic fracturing was implemented at a depth of $350 \mathrm{~m}$ in the mine since 2015 . The holes were drilled without the special tool and, thus, were curved and sometimes considerably deviated from the preset diameter of $76 \mathrm{~mm}$. All holes were drilled in the roofs, in the vertical plane, mostly in the line of the central axis of the excavation, or in cross direction. In 2016 the work situation impeded drilling to prepare new measurement stations as per the proposed design. In connection with this, we inspected 10 holes drilled and selected for the hydraulic fracturing tests in 2015. Based on the inspection with video probe, only 3 vertical holes in block 15 at measurement stations Nos. 5 and 6 were assumed as suitable for the repetitive experimentation.

At measurement station No. 5, in one hole, 6 hydraulic fracturing tests were performed at the distances of 5 and $5.5 \mathrm{~m}$ from the excavation boundary. At station No. 6, in two holes, 12 tests were carried out at the depths of 4-7 m. That holes were drilled without 
initiation slotting, and for this reason, only horizontal stresses were estimated using the hydraulic fracturing stress measurement.

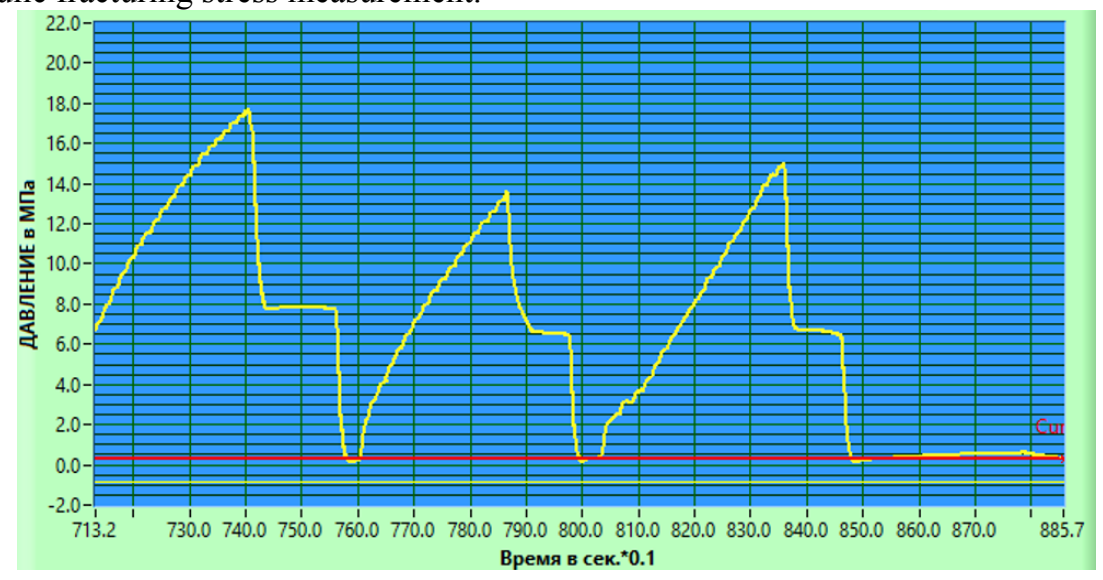

Fig. 4. Typical experimental pressure-time diagram.

After processing of the experimental data, we had $\sigma_{\min }=8.8-14.4 \mathrm{MPa}$ and $\sigma_{\max }=12.9$ 25.3 MPa. In the majority of the tests, the horizontal stresses exceeded 1.5-2 times the gravitational stress $(\approx 8.0 \mathrm{MPa})$.

Solikamsk Mine-2. The tests were carried out in the mine at a depth of $200 \mathrm{~m}$ in 2016. In the course of preparation of the measurement stations, the new-designed drilling equipment, drilling tool and the slotter were trialed and finished. At measurement station No. 7, two holes were drilled (vertical and inclined at the angle of $60 \mathrm{deg}$ ); at measurement station No. 8, three holes were drilled (one vertical hole and two holes at the angles of 30 and 60 deg to horizon). By the data of the directional hydraulic fracturing with initiation slots (made at the distance of $10 \mathrm{~m}$ from the test excavation boundary), the vertical stress $\sigma_{H}$ and the horizontal shear stress component $\sigma_{c}$ were estimated in the plane of measurement stations Nos. 7 and 8. Using the data obtained in the same holes in the section without slots (7-9 m away from the boundary of the excavation), the maximum and minimum horizontal stresses were determined using the classical formulas.

At measurement stations Nos. 7 and 8, 24 tests of hydraulic fracturing were performed all in all. After processing of the experimental data, we obtained: the vertical stress $\sigma_{H}=$ 6.7-7.1 MPa; the horizontal minimum stress $\sigma_{\min }=10-12.4 \mathrm{MPa}$ and maximum stress $\sigma_{\max }$ $=16.4-19.0 \mathrm{MPa}$; the horizontal shear stress $\sigma_{c}=15.6 \mathrm{MPa}$ in the plane of measurement stations Nos. 7 and 8 . The level of the horizontal stresses exceeded the vertical stress by $2-$ 3 times.

Solikamsk Mine-1. The tests were carried out in the mine at a depth of $250-350 \mathrm{~m}$ in 2016. At measurement stations Nos. 9-12, in the roof of an underground excavation, two holes were drilled: one vertical hole and one hole at the angle of $60 \mathrm{deg}$ to horizon. The initiation slots were made in the holes $6 \mathrm{~m}$ away from the roof at stations Nos. 10 and 11. First, the downhole survey tool was placed in the hole interval with initiation slots. In the later tests, the survey tool was stage-wise displaced toward the hole mouth and placed in the depth intervals of 5.5 and $5 \mathrm{~m}$ without slots. By the data obtained at measurement stations Nos. 9 and 12 in the holes without initiation slots, the maximum and minimum horizontal stresses were calculated.

All in all, at measurement stations Nos. 9-12, 33 hydraulic fracturing stress measurement tests were implemented. After processing of the test data, we had: the vertical stress component $\sigma_{H}=8.5-9.3 \mathrm{MPa}$; the horizontal stresses $\sigma_{\min }=10.9-13.6 \mathrm{MPa}$ and $\sigma_{\max }$ $=18.4-22.9 \mathrm{MPa}$; the horizontal shear stress component $\sigma_{c}$ was 17.7 and $17.5 \mathrm{MPa}$ at 
stations Nos. 10 and 11, respectively. The found values of the vertical stress are similar to the estimated stress due to overlying rock weight. The horizontal stresses are 2-3 times higher than the vertical stress.

Based on the calculated Lode-Nadai coefficient $\mu_{\sigma}=2 \cdot\left(\sigma_{2}-\sigma_{3}\right) /\left(\sigma_{1}-\sigma_{3}\right)-1$, the stress state in the roof rocks features prevalence of the tension shift mode of strain state. The general estimate of the stress field in the roof rocks is obtained by two invariants (see the table). Here, the major, minor and intermediate stresses $\left(\sigma_{1}, \sigma_{2}\right.$ and $\left.\sigma_{3}\right)$ are determined using the average values $\sigma_{\max }, \sigma_{\min }$ and $\sigma_{\mathrm{H}}$ or $\gamma \mathrm{H}$.

Table. Stress field in the roof rocks in underground excavations in Solikamsk Mines-1, 2 and 3

\begin{tabular}{|c|c|c|c|}
\hline Parameters, MPa & \multicolumn{3}{|c|}{ Solikamsk Mine } \\
\cline { 2 - 4 } Invariant I (average stresses) & 1 & 2 & 3 \\
\hline$\frac{1}{3}\left(\sigma_{1}+\sigma_{2}+\sigma_{3}\right)$, & 14.0 & 11.8 & 12.7 \\
\hline$T=\frac{1}{\sqrt{6}} \sqrt{\left(\sigma_{1}-\sigma_{2}\right)^{2}+\left(\sigma_{1}-\sigma_{3}\right)^{2}+\left(\sigma_{2}-\sigma_{3}\right)^{2}}$ & 6.01 & 5.50 & 6.12 \\
\hline
\end{tabular}

As seen from the table, the level of average stresses in roof rocks is similar in all mines. The intensity of shear stresses is reflective of the absence of hydrostatic stress in these rock mass areas.

Thus, the hydraulic fracturing stress measurement technique can be recommended for stress monitoring in salt rock mass. This technique allows determining stresses far from the boundaries of underground excavations. The drilling tool optimized during the experiments enables quality drilling in salt rocks, without curvature and at persistent preset geometry of holes.

The method of directional hydraulic fracturing with preliminary softening of boundaries of measurement holes by initiation slots has been proposed and trialed during the tests. To this effect, special slotters have been designed. This approach allows assessment of vertical stress.

In total, 75 tests of the hydraulic fracturing stress measurement have been performed in salt rock mass. It is found that stress state consists of unequal components: the vertical stress is similar to the value due to weight of overlying rocks, while the horizontal stresses exceed the gravitational stress by $2-3$ times.

The authors appreciate participation of A.V. Panov, Yu.M. Lekontsev, A.M. Vasiliev and I.V. Kolykhalov from the Institute of Mining, SB RAS, in the test procedures. The authors wish to express their thanks to R.Yu. Sapachev, VNIIGalurgia, for his assistance in the test organization.

\section{References}

1. B.C. Haimson, F.H. Cornet, Int. J. Rock Mech. Min. Sci., 4, 1012-1020, (2003)

2. F.N/ Cornet, B. Valette, J. Geophys. Res., 813, 11527-115373 (1984)

3. J-H. Synn, C. Park, Y-B. Jung etc. Int. J. Rock Mech. Min. Sci., 75, 44-55, (2015)

4. C.-Ch. Zhang, Q-H. Jiang, X. He etc., EJGE, 18, 2851-2862, (2013)

5. T. Yokoyama, K. Sakaguchi, T. Ito, Proc. Eng., 191, 862-868, (2017)

6. D.D. Bush, N Barton, Int. J. Rock Mech. Min. Sci. \&Geomech., 26, 6, 579-586, (1989) 
7. T.W. Doe, G. Boyce, Int. J. Rock Mech. Min. Sci. \& Geomech., 1989, 26, 6, 605-611, (1989)

8. V.A. Asanov, A.V. Evseev, V.N. Toksarov, V.V. Anikin, N.L. Beltyukov, Gorn. Zhurnal, 6, 40-44, (2013) [In Russian]

9. V.N. Toksarov, V.A. Asanov, A.V. Evseev, N.L. Beltukov, The 7th Int. Symp. In-Situ R. Str., Tampere, 501-508 (2016) [In Russian]

10. V.D. Baryshnikov, D.V. Baryshnikov, L.N. Gakhova, Int. Conf. Interexpo GEO-Sibir2016, 2, 181-184, (2016) [In Russian]

11. A.V. Leontiev, S.N. Popov, Gorn. Zhurnal, 3, 37-43, (2003) [In Russian]

12. Y.M. Lekontsev, A.V. Leontiev, Int. Conf. Interexpo GEO-Sibir-2016, 3, 181-184, (2016) [In Russian]

13. A.V. Leontiev, E.V. Rubtsova, Y.M. Lekontsev, V.G. Kachalsky, J. Min. Sci., 46, 1, 89-94, (2010) [In Russian]

14. J.R. Aggson, K. Kim, Int. J. Rock Mech. Min. Sci., 1987, 24, 1, 75-80, (1987) 